\title{
REOPERATION IN ADULTS WITH REPAIR OF TETRALOGY OF FALLOT: INDICATIONS AND OUTCOMES
}

Erwin N. Oechslin, MD

David A. Harrison, MD

Louise Harris, MD

Eugene Downar, MD

Gary D. Webb, MD

Samuel S. Siu, MD

William G. Williams, MD
Objective: The purpose of this study is to review indications, surgical procedures, and outcomes in adults with repaired tetralogy of Fallot referred for reoperation. Method: Sixty consecutive adults (age $\geq 18$ years) who underwent reoperation between 1975 and 1997 after previous repair of tetralogy of Fallot were reviewed. Mean age at corrective repair was $13.3 \pm$ 9.6 years and at reoperation 33.3 \pm 9.6 years. Mean follow-up after reoperation is $\mathbf{5 . 0} \pm \mathbf{4 . 9}$ years. Results: Long-term complications of the right ventricular outflow tract $(n=45,75 \%)$ were the most common indications for reoperation: severe pulmonary regurgitation (n $=23,38 \%)$ and conduit failure $(n=13,22 \%)$ were most frequent. Less common indications were ventricular septal patch leak $(n=6)$ and severe tricuspid regurgitation $(n=3)$. A history of sustained ventricular tachycardia was present in 20 patients $(33 \%)$ and supraventricular tachycardia occurred in 9 patients $(15 \%)$. A bioprosthetic valve to reconstruct the right ventricular outflow tract was used in 42 patients. Additional procedures $(n=115)$ to correct other residual lesions were required in 46 patients $(77 \%)$. There was no perioperative mortality. Actuarial 10-year survival is $92 \% \pm 6 \%$. At most recent follow-up, $93 \%$ of the patients are in New York Heart Association classification I or II. Sustained ventricular tachycardia occurred in 4 patients $(7 \%)$ during follow-up. Conclusions: Long-term complications of the right ventricular outflow tract were the main reason for reoperation. Mid-term survival and functional improvement after reoperation are excellent. (J Thorac Cardiovasc Surg 1999;118:245-51)
O erative correction of tetralogy of Fallot (TOF) has been performed for more than 40 years and is well established. Long-term outcome and quality of life of patients who survive the first 30 postoperative days are excellent, but patients continue to be at risk for longterm morbidity. ${ }^{1-5}$ An increasing number of adults with repaired TOF are having late complications such as arrhythmias, heart failure, and sudden death. These complications are a result of the deleterious effect of

From the Toronto Congenital Cardiac Centre for Adults, The Toronto Hospital, Toronto, Ontario, Canada.

Erwin Oechslin was supported by the Faculty of Medicine, University of Zurich, and the Stiefel Zangger Foundation, Zurich, Switzerland.

Received for publication May 27, 1998; revisions requested July 31, 1998; revisions received Oct 1, 1998; accepted for publication April 2, 1999.

Address for reprints: William G. Williams, MD, Hospital for Sick Children, 555 University Ave, Toronto, ON M5G 1X8, Canada.

Copyright (C) 1999 by Mosby, Inc.

$0022-5223 / 99 \$ 8.00+0 \quad \mathbf{1 2 / 1 / 9 9 0 9 9}$ important tricuspid and pulmonary regurgitation, right ventricular dysfunction, ventricular septal patch leaks, and stenosis of the right ventricular outflow tract (RVOT) and branch pulmonary arteries. ${ }^{1-9}$ Hemodynamic abnormalities and cardiac arrhythmias are indications for late reoperation after corrective repair. ${ }^{2,10,11}$ To date, the literature on reoperation has focused primarily on children or adolescents. ${ }^{10-13}$ The indications, the nature of reoperations, and the longterm outcomes have not been well defined in the growing population of adults after their transition from pediatric to adult care. The purpose of this study is to review indications, surgical procedures, and outcomes in adults with repaired TOF referred for reoperation.

\section{Methods}

Population. The study population consisted of 60 consecutive patients $(50 \%$ male) who underwent a reoperation between 1975 and March 31, 1997, at the Toronto Congenital Cardiac Centre for Adults (TCCCA). Ten patients (17\%) were referred from outside the province of Ontario. A total of 330 
Table I. Demographic data

\begin{tabular}{lcrrr}
\hline & Median & Mean & 1 SD & Range \\
\hline Age (y) & & & & \\
At corrective repair & 10.4 & 13.3 & 9.6 & $4.1-55.9$ \\
At recent reoperation & 31.3 & 33.3 & 9.6 & $20.6-61.9$ \\
At latest follow-up & 36.8 & 38.3 & 9.5 & $22.7-69.6$ \\
Follow-up interval (y) & & & & \\
$\quad$ Initial repair to reoperation & 20.0 & 6.9 & $6.0-36.4$ \\
$\quad$ After reoperation & & 5.0 & 4.9 & $0.3-21.4$ \\
\hline
\end{tabular}

adult patients (ie, age $>18$ years) with repaired TOF are being followed up at the TCCCA; therefore the 50 patients undergoing reoperation represent $15 \%$ of the total number of patients being followed up. In total, however, 1467 patients with TOF have been assessed in Toronto and would currently be over the age of 18 years. Therefore the 50 local patients requiring reoperation represent $3.4 \%$ of the total population at risk (personal communication, Dr Brian McCrindle, February 1998).

Medical and operative reports were reviewed to obtain the surgical techniques used for initial corrective repairs and to obtain details of reoperation indications, surgical procedures, perioperative complications, and late outcomes. Follow-up was obtained in all patients to 1997 except for 3 patients who were last seen in 1996. All 3 of these patients had a follow-up longer than 1 year and 2 longer than 5 years after their reoperation. Forty-eight of the 60 patients were followed up at TCCCA and reviewed by the authors. Two patients living in the Toronto area and 10 patients from outside the province of Ontario are being observed by their referring cardiologists.

The demographic data are presented in Table I. The mean age at corrective repair of 13.3 years (range 4.1-55.9 years) is older than current surgical practice. Initial corrective repair was performed during childhood or adolescence in 48 patients (80\%) and during adulthood (age $\geq 18$ years) in 12 patients (20\%).

Indication for reoperation. Patients with residual lesions after repair of TOF were considered for reoperation when their symptomatic status deteriorated or there was objective evidence of progressive right heart dysfunction including the onset of tricuspid insufficiency or ventricular or supraventricular arrhythmia. ${ }^{14}$

Complications of the RVOT were the main indication for reoperations in 45 patients $(75 \%)$, and these were performed $20.6 \pm 6.5$ years (7.4-36.4 years) after the initial corrective repair (Table II). A right ventricular systolic pressure higher than two thirds of the left ventricular systolic pressure or a pressure gradient of more than $50 \mathrm{~mm} \mathrm{Hg}$ across the RVOT was the threshold for recommending reoperation.

Pulmonary regurgitation is difficult to quantify and was not an indication for reoperation until there was evidence of increasing right ventricular dilatation, often with the onset of tricuspid regurgitation and usually associated with increased symptoms or onset of arrhythmia. Severe pulmonary regurgitation $(n=23)$ and conduit failure $(n=13)$ were the most frequent causes of RVOT complications. Of the 23 patients with
Table II. Major hemodynamic indications for reoperation*

\begin{tabular}{lrr}
\hline Primary lesion & $n$ & $\%$ \\
\hline RVOT complications & 45 & 75 \\
Severe pulmonary regurgitation & 24 & 40 \\
Conduit failure & 13 & 22 \\
RVOT obstruction & 5 & 8 \\
Severe PR and RVOT obstruction & 3 & 5 \\
VSD patch leak (Qp/Qs > 1.5) & 6 & 10 \\
Severe tricuspid regurgitation & 3 & 5 \\
Patent Blalock-Taussig shunt & 3 & 5 \\
Others & 3 & 5 \\
\hline
\end{tabular}

$R V O T$, Right ventricular outflow tract; $V S D$, ventricular septal defect; $P R$, pulmonary regurgitation; $Q p$, pulmonary blood flow; $Q s$, systemic blood flow.

"The table lists only the primary hemodynamic lesion leading to reoperation. Most patients have multiple lesions; in 29, there was atrial $(n=9)$ or ventricular $(\mathrm{n}=20)$ tachycardia.

severe pulmonary regurgitation, $17(74 \%)$ initially had the RVOT reconstructed with a transannular patch, a pulmonary valvotomy was performed in 3 , and an infundibular patch without pulmonary valvotomy was performed in 1 . The surgical techniques at initial corrective repair were unknown in the remaining 2 patients.

Of the 13 patients with conduit failure, 9 had insertion of a valved conduit at initial corrective repair, a mean of $19.4 \pm$ 5.4 years previously (range 12.1-30.5 years). In 3 of these 9 patients the conduit had been inserted at a reoperation 6.7 , 4.6, and 10.3 years after the initial repair and 4.9, 7.0, and 8.4 years before the most recent reoperation. Four patients without conduit implantation at initial repair underwent RVOT reconstruction with a valved conduit at a previous reoperation $7.4 \pm 5.9$ years (range 2.3-15.8 years) after the initial repair and $11.3 \pm 6.2$ years (2.6-17.2 years) before the most recent reoperation.

A history of sustained (ie, longer than 30 seconds) ventricular tachycardia was present in 20 patients, 17 of whom had RVOT lesions, 2 a ventricular septal defect, and 1 no hemodynamic lesion.

The functional class was New York Heart Association (NYHA) class I or II in 37 patients (62\%) and class III or IV in $23(38 \%)$ (Fig 1). The group in NYHA class $I(n=19)$ includes patients with ventricular arrhythmia associated with hemodynamic abnormalities and patients contemplating pregnancy who had important residual RVOT obstruction or conduit stenosis (right ventricular systolic pressure > two thirds of left ventricular pressure or gradient $>50 \mathrm{~mm} \mathrm{Hg}$ across the RVOT).

Surgical procedures. Thirty-five patients $(58 \%)$ underwent palliative procedures before their repair (BlalockTaussig shunt in 29, Waterston shunt in 4, and Potts anastomosis in 2 patients).

The surgical techniques used for initial repair of the RVOT are presented in Fig 2. A transannular patch $(\mathrm{n}=23)$ or a valved conduit $(n=9)$ was used in $53 \%$ of the study population. 


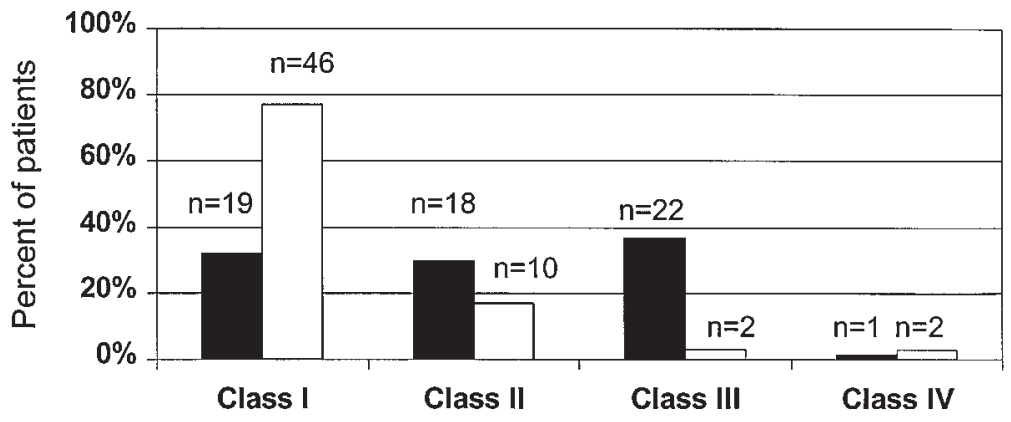

Before reoperation $\square$ After reoperation

Fig 1. Functional status (NYHA class) before and after reoperation. The condition of 35 patients (58\%) improved after reoperation. NYHA class I/II before $(\mathrm{n}=37,62 \%)$ versus after $(\mathrm{n}=56,93 \%)$ reoperation, $P<.05$. Class denotes New York Heart Association classification.

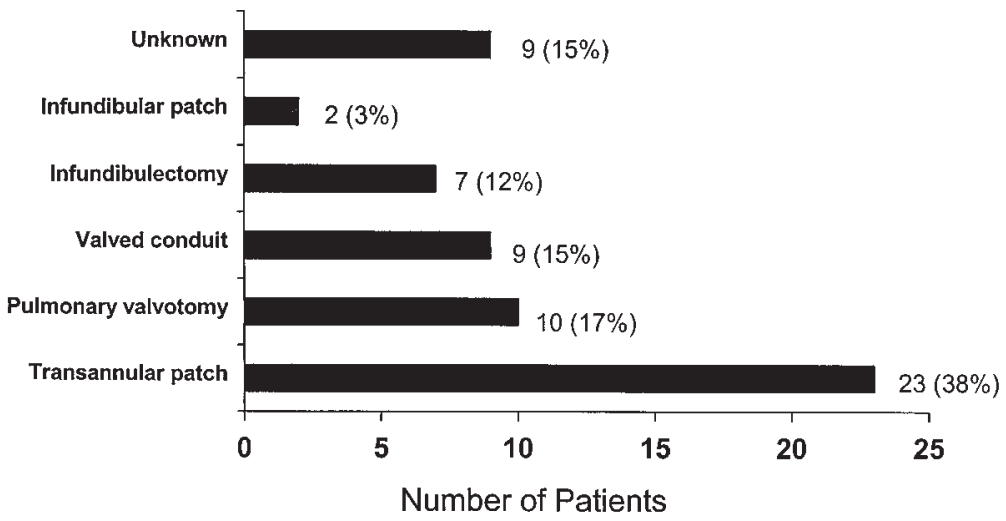

Fig 2. Surgical technique used for initial corrective repair. Transannular patch and valved conduit was used in $53 \%$ of patients. This percentage reflects the technique used during this era in Toronto.

Surgical procedures at the most recent reoperation are described as either primary procedures directed at correction of the major hemodynamic abnormality or as additional surgical procedures performed to repair associated abnormalities.

Previous reoperations after initial repair had been performed in 11 patients (18\%): 1 prior revision in 8, 2 revisions in 2, and 3 revisions in 1 patient. Eight of these patients had the reoperation during childhood or adolescence (age $<18$ years) and 3 patients during adulthood at another center.

\section{Surgical procedures for arrhythmias}

Ventricular tachycardia. A preoperative electrophysiologic study was part of the assessment in patients with a history of sustained ventricular tachycardia lasting more than $30 \mathrm{sec}-$ onds. Preoperative sustained ventricular tachycardia was documented in 20 patients (33\%).

Intraoperative mapping by the technique previously described ${ }^{15,16}$ was performed if monomorphic ventricular tachycardia was inducible at preoperative electrophysiologic study. Localized re-entry pathways of ventricular tachycardia were ablated with cryolesions during cardioplegic cardiac arrest.
Sixteen of 20 patients with sustained preoperative ventricular tachycardia had a monomorphic pattern and underwent intraoperative mapping. One or 2 pathways were identified in 11 patients who underwent ventricular cryoablation. The site of ventricular tachycardia was predominantly the infundibular septum adjacent to the ventricular septal defect patch $(\mathrm{n}=$ 10) or the right ventricular free wall adjacent to the previous ventriculotomy in 1 patient.

The 5 patients who did not undergo intraoperative cryoablation had noninducible ventricular tachycardia $(n=4)$ or multifocal origin $(n=1)$. Intraoperative mapping was not carried out in 4 patients with preoperative ventricular tachycardia because results of their preoperative electrophysiologic study were within normal limits $(\mathrm{n}=3)$ or because electrophysiologic evaluation was not available early in the series ( $\mathrm{n}$ $=1$ ).

Atrial arrhythmias. Nine patients had a history of supraventricular tachycardia consisting of intermittent atrial flutter in 4 and atrial fibrillation in 5. Intraoperative atrial mapping and cryoablation was used in the 7 patients with 
Table III. Primary and additional procedures

\begin{tabular}{lccc}
\hline Operative procedures & $\begin{array}{c}\text { As primary } \\
\text { procedure }\end{array}$ & $\begin{array}{c}\text { As additional } \\
\text { procedure }\end{array}$ & Total \\
\hline RVOT reconstruction & $45(75 \%)$ & 32 & 77 \\
Bioprosthetic valve & $42(70 \%)$ & 3 & 45 \\
RVOT aneurysmectomy & 0 & 14 & 14 \\
Other RVOT reconstructions & $3(5 \%)$ & 14 & 17 \\
VSD patch leak repair & $6(10 \%)$ & $5(8 \%)$ & 11 \\
Tricuspid valve surgery & $3(5 \%)$ & $8(13 \%)$ & 11 \\
Valve replacement & $2(3 \%)$ & 0 & 2 \\
Valve repair/ring & $1(2 \%)$ & $8(13 \%)$ & 9 \\
Closure of BT shunt & $3(5 \%)$ & $2(3 \%)$ & 5 \\
Pulmonary arterioplasty & $1(2 \%)$ & $23(38 \%)$ & 24 \\
Intraoperative EPS & $1(2 \%)$ & $19(32 \%)$ & 20 \\
Mapping & $1(2 \%)$ & $19(32 \%)$ & 20 \\
Atrial cryoablation & 0 & $7(12 \%)$ & 7 \\
Ventricular cryoablation & $1(2 \%)$ & $10(17 \%)$ & 11 \\
Closure ASD/PFO & 0 & $13(22 \%)$ & 13 \\
Others & $1(2 \%)$ & 13 & 14 \\
\hline Ond & &
\end{tabular}

One hundred fifteen additional procedures were performed in 46 patients (77\%). Numbers denote numbers of procedures, and \% denotes percentage of patients who underwent the procedure. Other procedures for RVOT reconstruction were infundibulectomy, RVOT patch, and pulmonary valvotomy. More than 1 procedure for RVOT reconstruction was usually required in the 45 patients $(75 \%)$ with RVOT complications as the main indications; 4 patients (7\%) undergoing reoperation for another main indication underwent RVOT reconstruction. The other primary procedure is aortic valve replacement. Other additional procedures include plication of the right atrial wall (n $=3$ ), oversewing of an aneurysmal ventricular septal defect patch $(\mathrm{n}=2)$, aorta-coronary bypass $(\mathrm{n}=2)$, occlusion of patent ductus arteriosus $(\mathrm{n}=2)$, insertion of an epicardial pacemaker leads $(n=2)$, patch enlargement of aortic arch and creation of a bypass graft from the ascending to descending aorta with Hemashield cardiovascular fabric (Boston Scientific Corporation, Boston, Mass) $(\mathrm{n}=1)$, and mitral valve repair $(\mathrm{n}=1)$. BT shunt, BlalockTaussig shunt; $E P S$, electrophysiologic study; $A S D$, atrial septal defect; $P F O$, patent foramen ovale; $R V O T$, right ventricular outflow tract; $V S D$, ventricular septal defect.

atrial tachycardia operated on after 1996. Cryolesions were applied between the tricuspid valve and inferior vena cava adjacent to the edge of the coronary sinus and extending the lesions up onto the atrial septum. The patients undergoing cryoablation had either atrial flutter $(n=4)$ or atrial fibrillation $(\mathrm{n}=3)$.

Statistical analysis. All data are presented as the mean value $\pm 1 \mathrm{SD}$. Probability of survival after reoperation was calculated by Kaplan-Meier analysis with the use of the SPSS program (version 7.0 for Windows 95, SPSS, Inc, Chicago, Ill). A $\chi^{2}$ test was performed to compare categoric variables.

\section{Results}

Sixty patients underwent repair of at least 1 residual lesion and 46 patients had an additional 115 associated procedures (Table III). The number of reoperations has increased in recent years (Fig 3). Seventy-two percent $(n=43)$ of all reoperations were performed after January 1, 1990.

Primary procedure. The primary procedures reflect the main indications for reoperation (Table III). RVOT reconstruction was performed in 45 patients. A bioprosthetic valve in the orthotopic pulmonary position was inserted in 42 of the 45 patients: the other 3 had a valve repair and RVOT patch $(\mathrm{n}=2)$ or a pulmonary allograft conduit $(\mathrm{n}=1)$.

Additional procedures. Additional procedures $(\mathrm{n}=$ $115)$ to correct secondary abnormalities at the time of reoperation were performed in 46 patients $(77 \%)$ (Table III). Combined procedures to reconstruct the RVOT and perform pulmonary arterioplasty, intraoperative electrophysiologic study, and closure of an atrial shunt were most frequent.

Perioperative morbidity and mortality. There were no perioperative deaths. Perioperative morbidity was $15 \%(\mathrm{n}=9)$ and included injury of the aorta and left coronary artery during sternotomy in 2 patients in whom there had been 3 or more previous sternotomies. In 1 of these 2 patients the postoperative course was further complicated by cardiogenic shock, sepsis, and sternal osteomyelitis. Other postoperative complications were postoperative bleeding necessitating resternotomy $(\mathrm{n}=3)$, sternal osteomyelitis $(\mathrm{n}=1)$, Klebsiella bacteremia resulting from endocarditis $(\mathrm{n}=1)$, a mild form of adult respiratory distress syndrome $(\mathrm{n}=1)$, and cardiogenic shock $(\mathrm{n}=1)$.

Late mortality by Kaplan-Meier analysis. Ten-year survival is $92 \% \pm 6 \%$ (Fig 4). Two deaths occurred during follow-up. A 36-year-old man died 8 months after closure of a large ventricular septal patch leak. Death was caused by severe pulmonary hypertension and pulmonary vascular disease. A 70-year-old man died 7.7 years after reoperation of end-stage myocardial failure. He underwent initial TOF repair at the age of 56 years.

Late outcome: Symptoms. NYHA classification improved in 35 patients (58\%) after reoperation. Fiftysix patients $(93 \%)$ are in NYHA class I or II at most recent follow-up (Fig 1). The condition of 4 patients deteriorated after reoperation, including that of 2 who died (described earlier), and 2 had progressive heart failure including a patient who required heart transplantation 10 years later.

Late outcome: Ventricular and atrial arrhythmias Atrial arrhythmia. Fifty-two patients (87\%) were in sinus rhythm at most recent follow-up. Among the 50 patients who were in sinus rhythm before the operation, $46(92 \%)$ remain in sinus rhythm. Among the other 4 patients, 1 had atrial fibrillation and 3 required pacing: 1 for late-onset complete atrioventricular block 7 months after the operation, 1 for bradycardia-tachycardia syndrome at 3 years, and 1 for syncope with a long HV interval. 


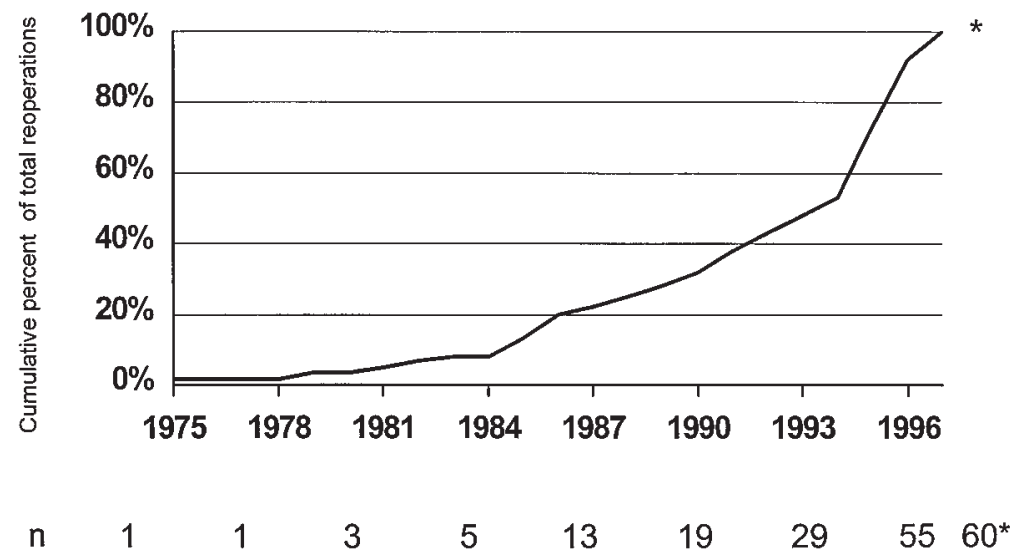

Fig 3. Cumulative percent of reoperations from 1975 until March 1997. There is a marked increase of reoperations in recent years. $N$ indicates numbers of reoperations. Asterisk denotes March 31, 1997.

Six of the 9 patients who had preoperative supraventricular tachycardia reverted to sinus rhythm, including all 4 patients who had cryoablation for atrial flutter. However, 2 of these 4 patients had transient supraventricular tachycardia necessitating treatment before resolving to sinus rhythm.

Atrial fibrillation persisted in 3 patients despite cryoablation and a fibrillation developed in a fourth de novo (described earlier).

Ventricular arrhythmia. Four patients (7\%) had a bout of sustained ventricular tachycardia during follow-up, compared with $33 \%$ of patients in whom it was present before the operation $(P=.01)$. Three of these 4 patients were among the 20 with preoperative ventricular tachycardia, an incidence of $15 \%$. The fourth patient had ventricular tachycardia de novo, an incidence of $2.5 \%$ among patients without preoperative ventricular tachycardia.

Among the 11 patients with ventricular tachycardia who were treated with cryoablation, $2(18 \%)$ have postoperative ventricular tachycardia, a prevalence that is not different from the 1 recurrence among the 9 patients with preoperative ventricular tachycardia who did not undergo cryoablation.

An implantable defibrillator was used in 1 of the patients with postoperative ventricular tachycardia. In the other 3 , tachycardia has been controlled with medication alone.

\section{Discussion}

Although long-term outcome and quality of life are excellent after repair of TOF, an increasing number of adults who have had the repair are having long-term complications leading to reoperation. ${ }^{1-4,8,9,14}$ In this

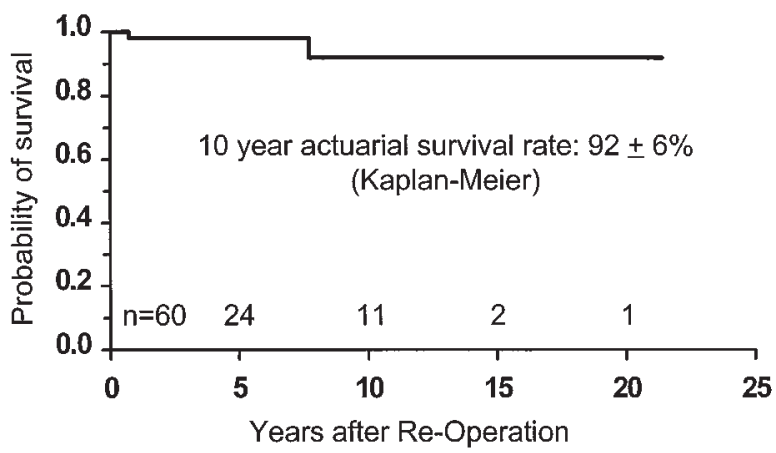

Fig 4. Kaplan-Meier actuarial survival analysis for patients after reoperation. $N$ represents the number of patients entering each time interval.

study, there is a marked increase in reoperations after 1990 (Fig 3), which reflects both the growing population of adults with repaired TOF and their propensity to become more symptomatic later in life. The cohort of adults undergoing reoperation is drawn from a population of 330 patients having regular follow-up in the Adult Clinic and from a total population at risk over age 18 years estimated at 1467 patients. All adults with repaired TOF have some residual hemodynamic lesions that are generally well tolerated for many years. Reoperation was recommended when there was a deterioration in the patient's clinical status or there were objective signs of deteriorating right heart function, often with the onset of ventricular or supraventricular arrhythmia. Reoperation may also be advised for patients who are free of symptoms but need an optimal clinical status to tolerate pregnancy. These guidelines for reoperation are described in the 
Consensus Conference on Adult Congenital Heart Disease. ${ }^{14}$

We found that long-term complications of the RVOT are the most prevalent reasons for reoperation and were often associated with sustained ventricular tachycardia. Pulmonary valve insufficiency was the most common lesion, and the condition of these patients improved substantially with implantation of an orthotopically positioned prosthetic pulmonary valve.

Operative risk was minimal and perioperative morbidity was $15 \%$. Severe complications during resternotomy were more common in patients with 2 or more previous operations.

Previous studies reporting the nature of reoperations after TOF repair have included all age groups with adult patients comprising only a small subset. ${ }^{2,13,17-19}$ Our experience regarding the nature of reoperation differs from that of others who report ventricular septal patch leaks as the main reason for reoperation. The difference may be attributed to the different study populations and to the length of follow-up. ${ }^{2}$ Although reports on restoration of the RVOT exist, ${ }^{13,14,17-20}$ pulmonary regurgitation is reported to be well tolerated through childhood and adolescence in the absence of important additional lesions. ${ }^{1,18,20}$ One report found a low incidence of reoperation for severe pulmonary regurgitation in the absence of important pulmonary artery stenosis. ${ }^{21}$ In contrast, another study observed a significantly lower 25-year survival in patients with a transannular RVOT patch compared with that of patients without a patch. ${ }^{22}$ The ability of a patient to tolerate pulmonary valve regurgitation varies considerably, and recent studies by Gatzoulis, ${ }^{23}$ Norgard,${ }^{24}$ and their associates have demonstrated the protective effect of a poorly compliant right ventricle.

The natural history of isolated congenital pulmonary regurgitation with an otherwise anatomically normal heart is benign during the first 20 to 30 years of life. ${ }^{25}$ However, the development of symptoms is evident, with increasing frequency after the age of 30 years. ${ }^{25}$ The concept that severe pulmonary regurgitation results in symptoms at longer-term follow-up is supported by our observations that $75 \%$ of patients in our study required reconstruction of the RVOT, often for symptomatic pulmonary regurgitation.

We have previously reviewed the long-term durability of the bioprosthetic valve in the pulmonary position. Actuarial survival in patients receiving a pulmonary bioprosthesis is $95 \%$ at 10 years, at which time $86 \%$ are free of valve reoperation. ${ }^{19}$ Other techniques of restoring the RVOT may be appropriate,,$^{13,17,18}$ but if a valve is required, a bioprosthesis is favored and is superior to a mechanical valve. ${ }^{26}$
Both ventricular (33\%) and supraventricular (15\%) tachycardia are common in patients with residual lesions late after TOF repair. Arrhythmias are known to be an important cause of long-term morbidity and mortality in patients with TOF, $, 5,7,8,27-29$ and sudden cardiac death is reported in several reports with long-term follow-up studies, with an incidence up to $6 \% .{ }^{28} \mathrm{~A}$ number of risk factors for ventricular arrhythmia have been identified. ${ }^{8,29}$ More recently, the association between chronic right ventricular volume overload (often indicated by QRS prolongation) and ventricular arrhythmia has been identified. ${ }^{27}$ The prevalence of ventricular tachycardia in our series decreased to $7 \%$ after reoperation. Most of this improvement is associated with repair of residual lesions, such as pulmonary insufficiency, and the role of cryoablation in treating either ventricular or atrial tachycardia is not yet clear. Nevertheless, intraoperative mapping has clarified the site and mechanism of the arrhythmia, and we anticipate that further experience will demonstrate a beneficial effect on direct arrhythmia control.

\section{Limitation of the study}

Our retrospective study was performed at a tertiary care center, and the patient population may be highly selected. However, the majority of operations for congenital heart disease in adults in Ontario (population $10,000,000$ ) are performed at our site, and we believe the spectrum of reoperations in TOF is representative for centers dealing with adults after TOF repair.

Subjective improvement of functional class is evident in our patients, but no objective data from hemodynamic studies or cardiopulmonary exercise tests are available. However, cardiorespiratory improvement after restoration of hemodynamic abnormalities has been demonstrated in children and adolescents with TOF. ${ }^{13,18,30}$

\section{Conclusions and implications}

The patients in this series underwent repair at a much older age (13 years), and repair was often preceded by 1 or more palliative operations. Neither of these situations pertains to present practice, in which primary repair is performed in the first year of life and the extent of RVOT resection is considerably less. However, the data from Shimazaki, Blackstone, and Kirklin $^{25}$ are highly relevant in pointing out that patients without surgery and with anatomically normal hearts, except for a congenitally incompetent pulmonary valve, will have symptoms of right heart failure later in life. In addition, our intraoperative electrophysiologic study has demonstrated that the site of ventricular arrhythmia is predominantly around the margins of 
the ventricular septal defect patch and not the ventriculotomy site per se. Therefore the infant with TOF undergoing repair in the present era will be at life-long risk of complications from the ventricular septal defect repair and from the RVOT residual disease. When these children reach adulthood, reoperation may be less prevalent and occur later in life, but it is unlikely that reoperation will be entirely avoided. The present review focuses attention on the late complications of patients undergoing repair of TOF in an earlier era but alerts us to potential problems that our patients of today may encounter.

\section{REFERENCES}

1. Lillehei CW, Varco RL, Cohen M, Warden HE, Gott VL, DeWall RA, et al. The first open heart corrections of tetralogy of Fallot: a 26-31 year follow-up of 106 patients. Ann Surg 1986;204:490-502.

2. Murphy JG, Gersh BJ, Mair DD, Fuster V, McGoon MD, Ilstrup $\mathrm{DM}$, et al. Long-term outcome in patients undergoing surgical repair of tetralogy of Fallot. N Engl J Med 1993;329:593-9.

3. Waien SA, Liu PP, Ross BL, Williams WG, Webb GD, McLaughlin PR. Serial follow-up of adults with repaired tetralogy of Fallot. J Am Coll Cardiol 1992;20:295-300.

4. Rosenthal A, Behrendt D, Sloan H, Ferguson P, Snedecor SM, Schork A. Long-term prognosis (15 to 26 years) after repair of tetralogy of Fallot. I. Survival and symptomatic status. Ann Thorac Surg 1984;38:151-6.

5. Harrison D, Harris L, Siu S, MacLaughlin C, Connelly M, Webb $\mathrm{G}$, et al. Sustained ventricular tachycardia in adult patients late after repair of tetralogy of Fallot. J Am Coll Cardiol 1997;30: 1368-73.

6. Vaksmann G, Fournier A, Davignon A, Ducharme G, Houyel L, Fouron JC. Frequency and prognosis of arrhythmias after operative "correction" of tetralogy of Fallot. Am J Cardiol 1990;66: 346-9.

7. Garson A Jr, Randall DC, Gillette PC, Smith RT, Moak JP, McVey P, et al. Prevention of sudden death after repair of tetralogy of Fallot: treatment of ventricular arrhythmias. J Am Coll Cardiol 1985;6:221-7.

8. Sullivan ID, Presbitero P, Gooch VM, Aruta E, Deanfield JE. Is ventricular arrhythmia in repaired tetralogy of Fallot an effect of operation or a consequence of the course of the disease? A prospective study. Br Heart J 1987;58:40-4.

9. Dunnigan A, Pritzker MR, Benditt DG, Benson DW Jr. Life threatening ventricular tachycardias in late survivors of surgically corrected tetralogy of Fallot. Br Heart J 1984;52:198-206.

10. Zhao HX, Miller DC, Reitz BA, Shumway NE. Surgical repair of tetralogy of Fallot. Long-term follow-up with particular emphasis on late death and reoperation. J Thorac Cardiovasc Surg 1985; 89:204-20.

11. Pome G, Rossi C, Colucci V, Passini L, Morello M, Taglieri C, et al. Late reoperations after repair of tetralogy of Fallot. Eur J Cardiothorac Surg 1992;6:31-5.

12. Misbach GA, Turley K, Ebert PA. Pulmonary valve replacement for regurgitation after repair of tetralogy of Fallot. Ann Thorac Surg 1983;36:684-91.

13. Bove EL, Kavey RE, Byrum CJ, Sondheimer HM, Blackman MS, Thomas FD. Improved right ventricular function following late pulmonary valve replacement for residual pulmonary insufficiency or stenosis. J Thorac Cardiovasc Surg 1985;90:50-5.
14. Connelly MS, Webb GD, Somerville J, Warnes CA, Perloff JK, Liberthson RR, et al. Canadian Consensus Conference on Adult Congenital Heart Disease 1996. Can J Cardiol 1998;14:395-452.

15. Chen TC, Parson ID, Downar E. The construction of endocardial balloon arrays for cardiac mapping. PACE 1991;14:470-9.

16. Downar E, Harris L, Kimber S, Mickleborough L, Williams W, Sevaptsidis E, et al. Ventricular tachycardia after surgical repair of tetralogy of Fallot: results of intraoperative mapping studies. J Am Coll Cardiol 1992;20:648-55.

17. Finck SJ, Puga FJ, Danielson GK. Pulmonary valve insertion during reoperation for tetralogy of Fallot. Ann Thorac Surg 1988; 45:610-3.

18. Warner KG, Anderson JE, Fulton DR, Payne DD, Geggel RL, Marx GR. Restoration of the pulmonary valve reduces right ventricular volume overload after previous repair of tetralogy of Fallot. Circulation 1993;88(Suppl):II189-97.

19. Yemets I, Williams W, Webb G, Harrison D, McLaughlin P, Trusler G, et al. Pulmonary valve replacement late after repair of tetralogy of Fallot. Ann Thorac Surg 1997;64:526-30.

20. Ilbawi MN, Idriss FS, DeLeon SY, Muster AJ, Gidding SS, Berry TE, et al. Factors that exaggerate the deleterious effects of pulmonary insufficiency on the right ventricle after tetralogy repair: surgical implications. J Thorac Cardiovasc Surg 1987;93:36-44.

21. Kirklin JK, Kirklin JW, Blackstone EH, Milano A, Pacifico AD. Effect of transannular patching on outcome after repair of tetralogy of Fallot. Ann Thorac Surg 1989;48:783-91.

22. Klinner W, Reichart B, Pfaller M, Hatz R. Late results after correction of tetralogy of Fallot necessitating outflow tract reconstruction: comparison with results after correction without outflow tract patch. Thorac Cardiovasc Surg 1984;32:244-7.

23. Gatzoulis MA, Clark AL, Cullen S, Newman CG, Redington AN. Right ventricular diastolic function 15 to 35 years after repair of tetralogy of Fallot: restrictive physiology predicts superior exercise performance. Circulation 1995;91:1775-81.

24. Norgard G, Gatzoulis MA, Morales F, Lincoln C, Shore DF, Shinebourne EA, et al. Relationship between type of outflow tract repair and postoperative right ventricular diastolic physiology in tetralogy of Fallot: implications for long-term outcome. Circulation 1996;94:3276-80.

25. Shimazaki Y, Blackstone EH, Kirklin JW. The natural history of isolated congenital pulmonary valve incompetence: surgical implications. Thorac Cardiovasc Surg 1984;32:257-9.

26. Kawachi Y, Masuda M, Tominaga R, Tokunaga K. Comparative study between St. Jude Medical and bioprosthetic valves in the right side of the heart. Jpn Circ J 1991;55:553-62.

27. Gatzoulis MA, Till JA, Somerville J, Redington AN. Mechanoelectrical interaction in tetralogy of Fallot: QRS prolongation relates to right ventricular size and predicts malignant ventricular arrhythmias and sudden death. Circulation 1995;92:231-7.

28. Quattlebaum TG, Varghese J, Neill CA, Donahoo JS. Sudden death among postoperative patients with tetralogy of Fallot: a follow-up study of 243 patients for an average of twelve years. Circulation 1976;54:289-93.

29. Zahka KG, Horneffer PJ, Rowe SA, Neill CA, Manolio TA, Kidd $\mathrm{L}$, et al. Long-term valvular function after total repair of tetralogy of Fallot: relation to ventricular arrhythmias. Circulation 1988;78(Suppl):III14-9.

30. Ilbawi MN, Idriss FS, DeLeon SY, Muster AJ, Berry TE, Paul MH. Long-term results of porcine valve insertion for pulmonary regurgitation following repair of tetralogy of Fallot. Ann Thorac Surg 1986;41:478-82. 